\title{
A PRÁTICA DO JORNALISMO INVESTIGATIVO NA DESCOBERTA DOS CASOS DE SEQUESTRO DE BEBÊS E CRIANÇAS DURANTE A DITADURA NO BRASIL (1964- 1985]
}

\author{
THE PRACTICE OF INVESTIGATIVE JOURNALISM IN \\ DISCOVERING CASES OF KIDNAPPING BABIES AND CHILDREN \\ DURING THE DICTATORSHIP IN BRAZIL (1964 - 1985)
}

Eduardo REINA ${ }^{1}$

Universidade Metodista de São Paulo | Brasil

\begin{abstract}
Resumo
Diante da falta de informações históricas, bibliográficas e na imprensa sobre o crime de sequestro de filhos de opositores ao regime militar durante a ditadura no Brasil (1964-1985), investigou-se a razão da invisibilidade deste crime de Estado e o que levou à ocultação desses fatos e das próprias vítimas. 0 estudo analisou 150 livros de memórias, história, reportagem e trabalhos acadêmicos sobre a ditadura publicados entre as décadas de 1960 e 2019, e 12 anos de edições dos jornais O Estado de São Paulo, Folha de S.Paulo, O Globo e Estado de Minas na busca por fatos que demonstrem que o trabalho de comunicação desenvolvido pelo governo militar invisibilizou as histórias desse crime cometido nas décadas de 1960 e 1970 e suas vítimas. Já para a apuração jornalística do fato em campo foram utilizadas entrevistas em profundidade, análise documental, técnicas de jornalismo investigativo. Comprovou-se que o JI, utilizando técnicas especiais de apuração, de forma independente e fora das redações, é capaz de revelar crimes que estavam ocultos e denunciá-los.

Palavras-chave

Jornalismo Investigativo; Sequestro de bebês e crianças; Ditadura no Brasil; Imprensa; Direitos Humanos

Abstract

Given the lack of historical, bibliographic and press information on the crime of kidnapping the children of opponents of the military regime during the dictatorship in Brazil (1964-1985), the reason for the invisibility of this state crime and what led to the concealment of these facts and the victims themselves were investigated. The study analyzed 150 books of memoirs, history, reporting and academic works on the dictatorship published between the 1960s and 2019, and 12 years of editions of the newspapers O Estado de S. Paulo, Folha de S.Paulo, $\mathrm{O}$ Globo and Estado de Minas in search of facts that demonstrate that the communication work developed by the military government made invisible as stories of this crime committed in the 1960s and 1970s and their deaths. For the journalistic investigation of the fact in the field, analysis of documents, investigative journalism techniques were chosen in-depth. It has been proven that the JI, using special investigation techniques, independently and outside the newsrooms, is able to reveal hidden crimes and report them. Keywords

Investigative Journalism; Kidnapping babies and children; Dictatorship in Brazil; Press; Human rights.
\end{abstract}

RECEBIDO EM 23 DE ABRIL DE 2020

ACEITO EM 05 DE AGOSTO DE 2020

1 JORNALISTA e escritor. Mestre em Comunicação Social pela Universidade Metodista de São Paulo (2020). Autor dos livros Cativeiro sem fim (2019), Depois da Rua Tutoia (2016), entre outros. Autuou em jornais e periódicos como diretor de redação, editor executivo, colunista, editor e repórter em São Paulo e interior. Também exerceu assessoria de imprensa. Contato: edu.reina@hotmail.com

João Pessoa - Brasil | ANO 7 VOL.7 N.2 | JUL./DEZ. 2020 | p. 54 a 76 Revista Latino-americana de Jornalismo | ISSN 2359-375X

Programa de Pós-Graduação em Jornalismo - UFPB

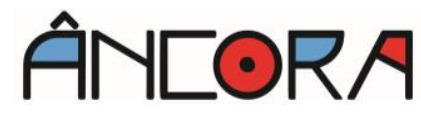




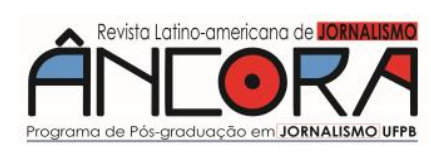

Eduardo REINA

\section{Introdução}

as décadas de 1960 e 1970, os governos militares na Argentina,
Brasil, Chile, Paraguai, Uruguai agiam de forma semelhante na
política e repressão, no método de tortura, na prisão e desaparecimento de opositores, na censura e uso de organizações clandestinas. Sem a constatação desse crime no território brasileiro, sob a justificativa da manutenção e preservação de doutrina de segurança nacional e da construção de uma sociedade livre do comunismo, também sequestraram cerca de 540 bebês e crianças filhos de militantes contrários ao regime (Padrós, 2005, 2009, 2011, 2012); (Madres y Familiares de Uruguayos Detenidos Desaparecidos, 2004); (Barreto, 2014); (Jabine, 2007); (Sábato, 1984); (Duhalde, 2013); (Secretaria Especial de Direitos Humanos da Presidência da República, 2009). Diante deste cenário, partindo da suposição de que sequestros semelhantes podem ter ocorrido aqui, surgiu a questão: como o jornalismo investigativo (JI) pode ajudar a desvendar e revelar esse tipo de crime cometido pelas forças militares durantes os anos de repressão no Brasil nas décadas de 1960 e 1970 ?

Daí originaram perguntas que ampliam o estudo e levam ao entendimento de como e porque esse crime praticado pelo Estado teria ficado invisibilizado por meio século no território nacional: quem seriam e onde estão as vítimas do crime de sequestro de filhos de militantes de oposição? Quais os fatores envolvidos na invisibilidade dos casos praticados nas décadas de 1960 e 1970? Como foi construída a narrativa, a comunicação na história e na mídia desse período histórico pelas forças militares e pela oposição?

A principal hipótese analisada é a ausência do tema no imaginário popular, nas pesquisas acadêmicas, nos livros de história e na mídia de massa como o maior fator contribuinte para que tal crime permanecesse esquecido dentro da História do Brasil. Outros fatores relevantes seriam a censura e a 
repressão, assim como a ação extremamente violenta dos militares, que evitaram a comunicação, reconhecimento e divulgação de informações sobre sequestro de bebês e crianças pelas forças armadas. 0 estudo avalia ainda 0 planejamento de comunicação realizado pelos governos militares e as ações desenvolvidas pela resistência, que teriam ficado aquém do necessário para se fazer entender sob outro prisma o cenário a que a nação estava submetida.

A investigação do fato começou antes do início da pesquisa de Mestrado, junto com o lançamento de romance sobre o tema - Depois da rua Tutoia (Reina, 2016) - para jogar luz sobre o assunto e despertar vítimas a se manifestar. Na sequência, entre 2017 e 2019, houve revisão bibliográfica de 150 livros sobre a ditadura; além da revisão de mais de 4 mil edições de quatro jornais de circulação para identificar reportagens sobre o assunto. Todo esse trabalho resultou no livro reportagem Cativeiro sem fim (Reina, 2019), que denuncia a existência de 19 casos de sequestro de filhos de militantes políticos pelos militares durante as décadas de 1960 e 1970 no Brasil, e o trabalho de Mestrado.

Aqui, como também na Argentina, o sequestro de filhos dos "inimigos" da pátria é a consolidação de uma lógica do uso ilimitado do recurso da violência como principal instrumento político (Sanjurjo, 2018). Tinha como objetivo "depurar" a sociedade e construir uma "nova ordem", como define o tenente-coronel português Hermes de Araújo Oliveira (1965). O desaparecimento de opositores e de pessoas ao seu redor é representado como tentativa de aniquilamento das pessoas, memórias e projetos políticos, cujo objetivo foi enclausurar o passado e evitar que o legado do "inimigo" fosse transmitido para as gerações futuras.

\section{Controle informacional}

Foi estruturada estratégia de comunicação para criar dissonância ao assunto, com o objetivo de tornar narrativas oficiais a base da historiografia nacional (Fico, 1997; Visacro, 2018). É preciso dizer que, segundo Piglia 


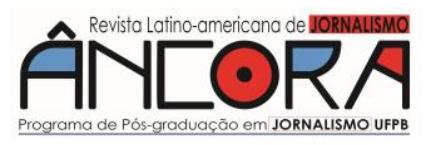

Eduardo REINA

(2015), o Estado é que detém o poder de narrar, tanto de criar histórias moralizantes ou de violência, quanto histórias que servem para ocultá-las, demarcando a legitimidade dos enunciados. Tudo como forma de coesão social, o que torna o conteúdo eficiente. A narrativa veiculada passa a ser vista como verdade e assume sua real potência, não apenas sendo verdade. A comunicação e o discurso punitivos às pessoas contrárias ao governo militar foram construídos de tal maneira e massificados pela mídia que a esquerda foi derrotada em sua posição e declarações sociais contrárias à repressão.

Tal manipulação, conforme observa Dines (1986) transforma a comunicação de massa, o circuito emissão-recepção-emissão, viciada quando não se introduz periodicamente novas ingredientes, versões, novas visões sobre os fatos e personagens. O que empobrece o entendimento histórico e o produto comunicacional.

\begin{abstract}
Estes novos ingredientes reacendem e estimulam o processo e, sem eles, o material informativo vai deteriorando e perdendo seu viço. Isto ocorre frequentemente nos sistemas fechados de comunicação, quando não há livre trânsito de informações, quando os estímulos intelectuais são bloqueados e o debate é empobrecido pela falta de ventilação. Ou nas redações seletivas, montadas na base de grupos ou "patotas"... Nesta situação, o jornal passa a ser um incessante bumerangue cultural: a audiência não recebe novas cargas de informações dos veículos e estes recebem do seu público, cada vez mais reprocessadas e usadas, as mesmas mensagens... De certa forma, esta é a situação pela qual passaram, nos últimos nãos, a sociedade brasileira e os seus veículos de comunicação, agravada pelo fato de que algumas destas alavancas, que teriam condições de injetar nova atmosfera, conformam-se aderindo voluntariamente ao estabelishment, quando o certo seria antecipar-se a ele (DINES, 1986, p. 59).
\end{abstract}

Na ditadura, a guerra informacional era contra o comunismo, contra os subversivos, que se tornaram acusados desde sempre de um crime contra a pátria brasileira. A censura, braço do terror de Estado, promoveu o esquecimento dos fatos, das vítimas e dos culpados pelos crimes. Gerou e contribuiu para o silenciamento da história e ocultação de personagens. A Comunicação, para os militares, é tão importante quanto o treinamento dos 
soldados, a logística e os recursos no enfrentamento do inimigo (Visacro, 2018). Alessandro Visacro, coronel do Exército brasileiro, aponta que até mesmo as narrativas a serem utilizadas devem ser controladas de acordo com o interesse do Estado no poder. Indica o desenvolvimento de campanha agressiva para garantir que a informação a ser repassada para o público e mostrar credibilidade. E manipular a opinião pública.

Esse processo é chamado por Irene Arruda de Almeida Cardoso (2001) como produção do "inexistencialismo", como "assassinato da memória". O trabalho comunicacional, aliado à adesão de empresas de mídia e outros setores da sociedade civil, legalizou o discurso baseado em fontes militares para registrar esse período da história da ditadura. Os meios publicitários e de imprensa legitimaram os acordos políticos e sociais sem contar com a participação da população. O povo foi excluído, conforme descreveu teoria de Habermas (1985, p. 258). Os Aparelhos Ideológicos de Estado funcionam de maneira massivamente prevalente pela ideologia (Althusser, 1970, p. 54).

A estratégia usada é chamada de "Controle Informacional", implementada pelos militares na "guerra de informações", que tem como objetivo a "vitória total" (Visacro, 2018, 2009). Na história da ditadura brasileira, há manipulação da informação com a predominância de discurso direcionado em fontes militares, com a primazia de poucas fontes de informações e quase nenhum documento comprovatório dos fatos narrados. Tal estratégia de guerra de narrativas cria o fim da clareza. Esse trabalho de narratividade estratégica também leva ao esquecimento, à invisibilidade, ao ocultamento de personagens e fatos históricos importantes que, no entender daqueles que estavam no poder, deveriam ser esquecidos, ocultados.

Já a ação da oposição não teve força ou estrutura para rivalizar às estratégias comunicacionais dos militares (Sá, 2004; PCdoB, 2005; Gaspari, 2002). No Araguaia, os guerrilheiros do $P C d o B$ agiram sob estrutura precária e uma rede de informações inexistente (Pomar, 1980; Fundação Mauricio Grabois e Arroyo, 2009; Nossa, 2012). Funcionava com base na oralidade, 


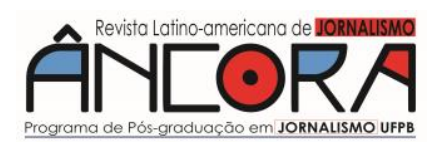

Eduardo REINA

panfletos ou edições de jornais que raramente chegavam às mãos da população (de maioria analfabeta) e dos próprios guerrilheiros. A rede de comunicação da oposição voltada para fora do Araguaia era mais rudimentar, composta por periódicos clandestinos, cujos jornais ficaram sob censura e pesada repressão. Foi realizada também veiculação de informações por rádio, via Albânia e China, cujo alcance e resultados são desconhecidos no Brasil. Como diz Bourdieu (1989, p.10), ao analisar as produções simbólicas como instrumento de dominação, as ideologias servem aos interesses particulares que tendem a apresentar como interesses universais, comuns ao conjunto do grupo, mas atendem à classe dominante.

Era fácil exercer a manipulação informacional na ditadura. Além da censura e da violência, os militares tinham a caneta para assinar leis e liberar verbas para pagar ações publicitárias direcionadas. Em 1976, somente entre março e setembro, a Assessoria Especial de Relações Públicas (Aerp) e seu órgão sucessor, Assessoria de Relações Públicas (ARP), veiculou apenas nos canais de televisão de São Paulo 12 mil mensagens (Fico, 1997, p. 110). Os generais criaram filmes ufanistas, como o "Este é uma país que vai pra frente", dentro da campanha de divulgação do governo, de suas ações e do que era chamado de "guerra psicológica". A veiculação do material era gratuita, mas se fosse cobrada custaria em torno de Cr\$ 20 milhões. Valor que na época corresponderia ao dobro dos gastos com publicidade do maior anunciante brasileiro, a empresa Gessy-Lever. O objetivo era criar pauta de preocupação cívica e estabelecer um tipo de "cidadania decorativa", que permitia a presença ou a "participação" de todos através de "iniciativas adjetivas", secundárias (Fico, 1997).

Enquanto isso, os grupos de esquerda enfrentavam a força do Estrado a bala e dispunham de acanhado aparato de comunicação para a disputa pela narrativa, pela divulgação de notícias sobre a repressão e mesmo para fazer comunicação entre si. A estrutura da Ação Libertadora Nacional (ALN), de 
Carlos Marighella, dispunha de setores de imprensa, de apoio logístico, de massas - subsetor estudantil e operário - e grupos táticos armados. A comunicação era realizada através de material impresso ou de forma oral. A Vanguarda Popular Revolucionária (VPR) possuía uma coordenação geral à qual se subordinavam os setores logístico, urbano - imprensa, estudantil e operário - e de campo. Já a Vanguarda Armada Revolucionária-Palmares (VAR-Palmares) dispunha de setor de luta principal (atividades de logística e de treinamento), e setor de luta secundário (inteligência e propaganda) (Visacro, 2009).

No Araguaia, os integrantes do PCdoB dispunham apenas de contatos pessoais com moradores e camponeses. Inicialmente, o modo de comunicação era a conversa; informação passada oralmente, sem registro formal (PCdoB, 2005), efetivada durante os trabalhos de mutirões. Para tentar romper a bolha que espremia a rede de comunicação entre dirigentes e militantes do PCdoB no Araguaia, passaram a utilizar o noticiário veiculado por rádios AM, a partir de boletins em português transmitidos via Albânia e China (PCdoB, 2005; Sá, 2004). Havia preconceito no uso extensivo da comunicação, como já identificado por Enzensberger (1978) ao estudar a teoria da comunicação relacionada ao marxismo. Hans Magnus Enzensberger aponta que a esquerda tinha conhecimento da importância do uso eficiente dos meios de comunicação para propagandear suas ações e ganhar a adesão popular, mas os hostilizava por entender que a mídia podia ser reduzida à manipulação, que era/é exercida pelo capitalismo de forma eficiente (1978, p. 59-64).

Os guerrilheiros usaram o jornal $A$ Classe Operária, levado clandestinamente à região. Utilizaram ainda boletins mimeografados, onde surge novo obstáculo comunicacional: a maioria dos habitantes do Araguaia era analfabeta, segundo o Mapa do analfabetismo no Brasil (Ministério da Educação, 2001). De acordo com o Censo Demográfico do IBGE, na década de 1970, a taxa de analfabetismo entre a população com idade de 15 anos ou mais era de $33,7 \%$ na região. Há relatos do uso de "meios mais modernos" de 


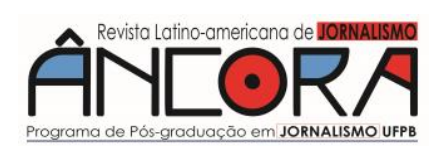

Eduardo REINA

comunicação entre os militantes, como rádios transmissores (PCdoB, 2005, p. 65). Mas não deu certo. A logística para compra, entrega e armazenamento de baterias portáteis era complicada e cara.

Sá (2004) reconhece em seu texto de memórias a ineficácia do trabalho de comunicação na guerrilha. O comandante guerrilheiro Ângelo Arroyo (2009) classificou o problema na área de comunicação do levante desempenhada pelo PCdoB no Araguaia como "erro grave" porque "não soube dar o necessário equilíbrio entre propaganda armada, criação de uma base política de massa e ações militares". Pomar (1980) ainda ressalta a "falta de rede de informações" e da precariedade da rede existente como fatores delicados na disputa com as forças militares.

\section{Jornais e livros - 0 registro na história}

Parte do levantamento e análise desta pesquisa fez a revisão bibliográfica de 150 livros e textos acadêmicos sobre a ditadura publicados de 1964 a 2019, num período de 55 anos. Essa revisão bibliográfica fundamentou descobertas ocorridas durante o estudo em campo, com a procura das vítimas reais, entrevistas orais e checagem de fatos e informações através de documentos, fatos e personagens levantados na revisão bibliográfica e no trabalho de campo. A escolha das obras lidas levou em consideração aquelas que versam sobre a ditadura e especificamente sobre a guerrilha do Araguaia, cujos autores são jornalistas, pesquisadores acadêmicos, religiosos, historiadores, militares, militantes políticos. A definição das obras revistas também levou em consideração parte da pesquisa em campo já realizada, desde 2016, que orientava a existência desse crime, pessoas envolvidas e local do ocorrido. São obras desde editoras pequenas e independentes, até aquelas de grande circulação ou mesmo editadas pelos próprios autores.

Somente dez, ou 6,66\%, contêm menções diretas ou indiretas a esse tipo de crime na ditadura do Brasil ou sobre as vítimas de sequestros e seus 
familiares. A história da guerrilha do Araguaia foi descrita por historiadores, jornalistas e pesquisadores; contudo esses trabalhos trazem poucos e sempre os mesmos personagens envolvidos, porque utilizam como fonte as próprias forças militares ou personagens ligados a eles. Dos dez livros que citam existência de casos do crime, apenas Direito à Memória e à Verdade: histórias de meninas e meninos marcados pela ditadura / Secretaria Especial dos Direitos Humanos (2009), aponta literalmente o fato e vítimas, o que restringe a percepção da existência desse crime praticado pelos militares.

O primeiro livro a citar indiretamente o crime é $A$ justiça do lobo posseiros e padres do Araguaia (1986), de Ricardo Rezende Figueira. O autor refere-se a José Vieira, que teve o pai - Luís Vieira - assassinado pelo Exército. José é uma das vítimas de sequestro (Reina, 2019). Mas os nomes de José e Luiz não constam no livro de Figueira, há somente descrição do fato que os envolveu. Um livro que cita José Vieira e mantém o mesmo silêncio sobre a verdadeira história desse filho de camponês é Guerrilha do Araguaia - a esquerda em armas, de Romualdo Pessoa Campos Filho (2012). Esse autor complementa informações e nomes à narrativa de Figueira no livro de 1986.

Autor de obra de destaque sobre a ditadura, o jornalista Elio Gaspari copia informações de Campos Filho. Em $A$ Ditadura Escancarada (2002) Gaspari menciona relato sobre Luiz Vieira, pai de José, como lavrador simpático aos guerrilheiros $(2002$, p. 441)². A nota de rodapé no 263 se refere à história de José Vieira (2002, p. 455), mas ao contar a prisão do guerrilheiro Piauí e repetindo informação de Campos Filho. Num outro parágrafo da obra, Gaspari mostra que realmente tinha conhecimento do sequestro de filhos de lavradores. Cita existência de seis casos de filhos de lavradores que estiveram nas mãos das forças militares, mas denomina a operação de sequestro dos adolescentes como "poupar" os garotos. Nesse trecho, Gaspari volta à história de José dizendo que o rapaz havia sido levado para a prisão. Descreve o

\footnotetext{
2 Nota de pé de página número 199.
} 


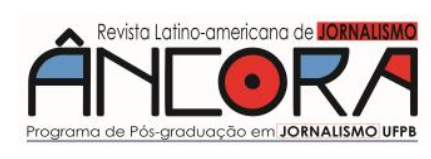

Eduardo REINA

itinerário que a vítima percorreu, levado para a capital paraense e depois para Altamira. Toda essa história foi confirmada em 2017 por José Vieira a esta pesquisa, o que leva a crer que Gaspari tinha conhecimento do que foi descrito nos depoimentos e relatórios militares usados para escrever seus livros sobre a ditadura. Mas narrou o ocorrido de outra forma, com viés pró-militares.

A saga da invisibilidade das histórias de sequestro de filhos de camponeses do Araguaia por militares está mantida no livro Dos filhos deste solo - mortos e desaparecidos políticos durante a ditadura militar: a responsabilidade do Estado (2008), de Nilmário Miranda. É contada a história de Luís Vieira em sete linhas de texto e indicada nova pista do que aconteceu com esse homem em 1974. Mas novamente o nome de José não é citado e a referência a ele aparece na última frase.

Mesmo tratamento é dado ao caso da família Vieira pelo jornalista Leonêncio Nossa, em Mata! O major Curió e as guerrilhas no Araguaia(2012). O nome do patriarca "Luizinho" aparece quando o repórter fala sobre a captura de camponeses pelo Exército em São Domingos do Araguaia (p. 167). Mas não há referência sobre o crime.

Outro guerrilheiro do $\mathrm{PCdoB}$ morto no Araguaia é citado em 22 páginas por Nossa (2012, p. 16, 22, 23, 97, 100, 101, 102, 103, 104, 137, 138, 175, $176,182,183,186,187,188,220,324,390$ e 413). É o cearense Antônio Teodoro de Castro, codinome Raul, pai da bebê sequestrada Lia Cecília Martins, cuja história é revelada pelo JI nesta pesquisa e no livro Cativeiro sem fim (Reina, 2019). Nas 22 citações sobre Antônio Teodoro não há uma única referência à filha que o guerrilheiro teve no Araguaia com mulher até hoje desconhecida. O mesmo jornalista cita o filho que outro guerrilheiro, Osvaldo Orlando da Costa, o Osvaldão, teve com Maria Viana da Conceição: Giovani. Das 150 obras sobre a ditadura e a guerrilha do Araguaia revisadas, Nossa é o único que relata informação parcial sobre o sequestro do filho do guerrilheiro Osvaldão.

João Pessoa - Brasil | ANO 7 VOL.7 N.2 | JUL./DEZ. 2020 | p. 54 a 76 
Menção indireta ao sequestro de bebês e crianças na região do Araguaia é do jornalista Hugo Studart em $A$ lei da selva - estratégias, imaginário e discurso dos militares sobre a Guerrilha do Araguaia (2006). Studart é filho de Jonas Alves Corrêa, militar da Aeronáutica que atuou na guerrilha do Araguaia. O jornalista também não trata José Vieira como vítima de sequestro, dizendo que ele foi preso em janeiro de 1974 (p. 379), pois estava incluído numa lista que relaciona "camponeses recrutados para a guerrilha". Studart cita no mesmo livro (2006) a morte do guerrilheiro Antônio Teodoro de Castro, ( $p$. 329, 351 e 357). Mas não faz menção ao fato de o militante comunista ser pai de Lia Cecília, bebê sequestrada no Araguaia. O mesmo autor escreveu Em algum lugar das se/vas amazônicas: as memórias dos guerrilheiros do Araguaia (1966-1974) (2013), e também não cita os outros casos de sequestro.

Parte das informações publicadas por Studart são baseadas em fontes e documentos oficiais que já haviam sido reproduzidas em 2005 pelos jornalistas Taís Morais e Eumano Silva em Operação Araguaia - os arquivos secretos da guerrilha. Esse livro reproduz narrativa idêntica à descrita por Miranda (2008) sobre a prisão de Piauí na casa de Antônio Almeida, tio de José Vieira (2005, p. 583). José não é citado.

A história de José Vieira e de seu pai ganha novas cores no livro do tenente José Vargas Jimenez, que atuou em grupos de combate do Exército sob o codinome Chico Dólar. Em Bacaba - memórias de um guerrilheiro de selva da guerrilha do Araguaia (2007) Jimenez descreve José como "inocente útil" que "passou a nosso colaborador" (p. 57). Sobre Antônio Teodoro de Castro, o militar cita a data de 27 de fevereiro de 1974 como dia de seu assassinato (p. 60).

A Comissão da Verdade do Estado de São Paulo da Assembleia Legislativa do Estado de São Paulo, em Infância roubada, crianças atingidas pela ditadura militar no Brasil (2014), relata depoimento de Lia Cecília Martins (p. 305-306), filha de Antônio Teodoro de Castro. Ela foi levada por militares para a cidade de Belém, deixada em orfanato e depois adotada por casal local. 


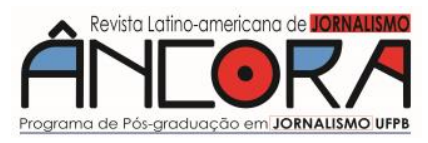

Eduardo REINA

Outra obra institucional, da Secretaria Especial de Direitos Humanos da Presidência da República, cita o sequestro de Lia Cecília: Direito à Memória e à Verdade - histórias de meninas e meninos marcados pela ditadura (2009, p. 86-87). Mas a informação é baseada em reportagem veiculada pelo O Estado de São Paulo, de 14 de julho de 2009, de Leonêncio Nossa e versa sobre o sequestro de Giovani, filho do guerrilheiro Osvaldão, e a busca do corpo de Antônio Teodoro de Castro pelos familiares. O mesmo livro deixa registrada a história, de forma rápida e sem profundidade, o caso de Maria Bezerra de Oliveira, que teve dois filhos sequestrados pelos militares no Araguaia na década de 1970 - Juracy e Miracy (p. 83).

Por fim o livro Os fuzis e as flechas: histórias de sangue e resistência indígena na ditadura (2017), do repórter Rubens Valente, conta que em 1966, crianças Xavante Marãiwatsédé foram levadas com anuência de militares e órgãos governamentais que tinham como missão defender os próprios indígenas.

Análise exploratória quantitativa nos jornais O Estado de São Paulo, Folha de São Paulo, O Globo e Estado de Minas, entre abril de 2003 e março de 2014, verificou a existência de nove matérias (0,205\%) sobre o tema, indicando a opacidade do fato junto à mídia de massa brasileira, como preconizou o trabalho de comunicação das forças militares. Reflete, sobretudo, situação já descrita por Bauman (2014), que apontou os princípios estratégicos de comunicação daqueles que estão no poder, através da "evitação e descompromisso" e, principalmente, a "invisibilidade" dos fatos (2014, p. 54$55)$.

A análise exploratória quantitativa é resultado de pesquisa on-line no acervo digitalizado de O Estado de São Paulo, Folha de São Paulo, O Globo e Estado de Minas. A escolha desses quatro periódicos deu-se em virtude de serem os que veicularam notícias sobre sequestro de bebês e crianças por militares durante a ditadura no período 1964-1985, uma vez delineado o tema 
a ser pesquisado, foi realizada busca no acervo digitalizado das empresas, através de busca em fonte aberta. A ferramenta propiciou a constatação das nove reportagens sobre o tema. Importante destacar que há a reprodução dessas matérias geradas por O Estado de São Paulo, Folha de São Paulo, 0 Globo e Estado de Minas em outros periódicos no país, mas que foram desconsiderados, pois apenas veiculam a notícia original destes quatro jornais. Definido que o universo de estudo em O Estado de São Paulo, Folha de São Paulo, O Globo e Estado de Minas, foram quantificadas quantas matérias produzidas a respeito do tema. A etapa subsequente foi delimitar o período a ser estudado. Optou-se por adotar como data de início a primeira matéria publicada sobre o tema; e a data final foi aquela da última publicação realizada como fim do período a ser estudado. Assim, a coleta de dados concentrou-se no levantamento em 12 anos de publicações, entre 25 de abril de 2003 e 18 de março de 2014.

Somente Folha de S.Paulo e O Estado de São Paulo usam a palavra sequestro nos textos. O Globo optou pela palavra desaparecimento e Estado de Minas usou rapto. Nas nove matérias publicadas não há explicação para a motivação do crime. Todas as reportagens falam em "adoção" pelos militares. Também não há referência ao mesmo crime realizado ou registrado em outras regiões brasileiras. Somente três das nove reportagens nomeiam o possível autor do crime de sequestro. Folha de S. Paulo, em 25 de abril de 2004, cita o nome do tenente Antônio Essílio Azevedo Costa, que levou Juracy para Fortaleza e o registrou em cartório como filho biológico. Mesmo caso é relatado pelo Estado de Minas em 2013, ao entrevistar a mãe de Juracy (Maria Bezerra de Oliveira). As reportagens mineiras citam os nomes de Antônio Essílio e de João Lima (sargento apropriador de Miracy). Nenhuma reportagem apresenta entrevista com militares envolvidos.

\section{O JI e sua contribuição para a história}




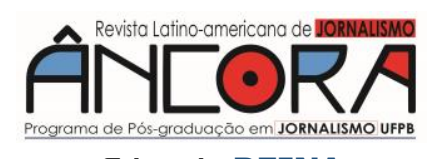

Eduardo REINA

Uma das principais finalidades do jornalismo é fornecer aos cidadãos as informações que necessitam para serem livres (Lopes et al, 2003). Essas informações só podem se tornar públicas com liberdade, uma das premissas do jornalismo investigativo, que se propõe a reconstruir acontecimentos importantes, promover reformas, expor injustiças, desmascarar fraudes, divulgar o que o poder público, o Estado, quer ocultar, além de informar os leitores (Lopes et al, 2003; Fortes, 2005). Alberto Dines afirma que jornalismo é arrumar, referenciar, investigar, distinguir circunstâncias (1986, p. 18). Em discussão sobre a importância do jornal, Dines aponta que o papel do jornal é ser necessário para a cultura, para a política, economia, saúde, cultura e cotidiano da vida em sociedade. Defende total independência das empresas jornalísticas e dos jornalistas do "status quo" e governo de plantão - de forma isenta e independente - como meio de exercer a profissão de forma ética e coerente.

A evolução dos métodos de JI, em busca de resultados, exige práticas complexas de investigação fora do ambiente de redação. Há o modo de cobertura convencional de notícias, passiva, dentro das redações; e depende amplamente, quando não inteiramente, de materiais fornecidos por políticos, governos, empresas, assessorias. Já o JI independente, mesmo com poucos recursos, está vinculado somente ao esforço do próprio repórter, com material reunido ou gerado a partir da própria iniciativa. O profissional deste tipo de reportagem atua de modo solitário e, acima de tudo, consegue entrever informações, fatos, situações e pessoas que a maioria dos jornalistas entende como inexistente (Souza, 2002; Quesada, 1987).

Costuma-se dizer que o jornalismo é o primeiro rascunho da história. Em contraste, o jornalismo investigativo é o primeiro rascunho da legislação (Burgh, 2008), porque a notícia que promove denúncia contra o Estado, governo e governantes de plantão, ou sociedade civil e empresarial, chama a atenção para falhas do sistema de regulamentação social e para formas como

João Pessoa - Brasil | ANO 7 VOL.7 N.2 | JUL./DEZ. 2020 | p. 54 a 76 
esse sistema pode ser logrado pelos ricos, poderosos e corruptos. No processo de apuração e checagem da verdade, destaca Kovach et al (2003, p. 243), deve-se lembrar sempre que a forma nunca pode determinar a substância - a técnica nunca deve alterar os fatos. A forma como o jornalista usa a narrativa deve sempre ser governada pelos princípios da exatidão e da veracidade. No JI impera a necessidade de se buscar, sempre, novas fontes para obter informações e documentos. Fontes que vão além daquelas que estivessem na cena do crime em questão, ou envolvidas com o caso em investigação (Santoro, 2004, p. 62).

Lugar de repórter é na rua, atrás da notícia, cara a cara com a fonte. A verificação minuciosa de cada um dos dados obtidos das diferentes fontes de informação, orais ou escritas, é tarefa que o repórter investigativo deve realizar constantemente (Quesada, 1987, p. 83-84), pois a questão da checagem e rechecagem, da verificação, da informação é fundamental e única maneira de dar solidez à pesquisa jornalística. A verificação de informações é essencial porque é o único meio de dar força científica à pesquisa jornalística (Quesada, 1987, p. 84) e ao produto dela resultante.

Há outras estratégias para levantar informações e dados sobre os documentos/objetos/fatos/personagens/informações a serem apurados nas reportagens investigativas. Trata-se da revisão constante de textos já publicados por outros repórteres, que pode se desdobrar em novos focos históricos e jornalísticos, conforme observa Montserrat Quesada (1987) e reforça Hunter et al(2013) ao destacar que a pesquisa em profundidade quase sempre traz à tona novas possibilidades para uma história, que até então eram desconhecidas no começo da investigação; e que demandam novas hipóteses que possam, à sua vez, ser verificadas. Conforme destaca o professor Daniel Santoro, da Universidade de La Plata (AR), é preciso aprender a ler nas entrelinhas e também fazer uma leitura crítica daquilo que as fontes falam e informam (Santoro, 2004, p. 64-65). 


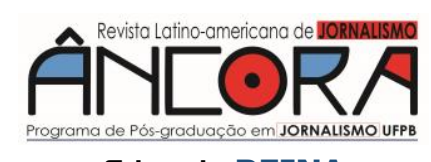

Eduardo REINA

Junto a esse processo de trabalho detalhado, demorado e custoso, deparamos com a situação das redações dos veículos de comunicação, que operam num momento onde reportagens se tornam cada vez mais rasas e factuais (Dines, 1986; Medina, 1978, 2003; Fortes, 2009), e em período que valoriza a rapidez na veiculação das informações; sem contar com a sobreposição do fator empresarial (lucro) à qualidade das reportagens, o que cria obstáculo às reportagens investigativas de qualidade. Conforme observa Cremilda Medina (1978), as empresas industriais de comunicação de massa, assim como os jornais, ainda mantêm viés autoritário e descompasso para com o que vem acontecendo no país democrático. O que impediria veiculação de noticioso político menos alinhado com o autoritarismo e conservadorismo.

Teóricos do Jornalismo como Dines (1986); Medina (1978, 2003); Fortes (2009) e Abramo (1988) apontam que o JI foi perdendo espaço nas redações e nas páginas de jornais ao longo do tempo, desde o processo de censura implantado durante o período da ditadura (1964-1985), passando pela abertura política, e chegando aos dias de hoje (Dines, 1986, p. 21, 27, 94, 98). Isso transformou o jornalismo de campo, onde repórteres iam em busca de pauta e promoviam investigações em vários setores da sociedade e na rua, num "jornalismo de gabinete". Deixou-se de lado a busca de fatos, abrindo-se mão dessa prerrogativa profissional, em detrimento do exercício de um jornalismo abastecido por informações que chegam prontas às redações. Ações que transformaram a mídia de massa numa produtora de informação pasteurizada, conforme analisam Dines (1986) e Medina $(1978,2003)$ ao abordar modo de atuação, estrutura e operação das redações jornalísticas atreladas ao poder hegemônico.

Todos esses obstáculos precisam ser transpostos para que se exerça livremente a premissa de desenvolver um jornalismo investigativo de qualidade no Brasil. A dificuldade em se mostrar outras vertentes da história da ditadura que não foram contadas ainda necessita da ação de jornalistas (Souza, 2002, 
p. 239), que têm entre seus principais papeis na sociedade o de esclarecer e denunciar ocorridos na história. Para ultrapassar essa barreira que se enraizou nas redações é necessário adotar uma nova postura, resgatar o jornalismo praticado fora das redações e pelo telefone, promover as ações do "jornalista em pé" (Medina, 2016). É necessário driblar essa estrutura sólida existente. Para que a notícia veiculada nas páginas dos jornais contenha valor agregado e também fuja das notas e versões oficiais, é necessária a quebra de rotina das redações, avaliam os estudiosos (Dines, 1986; Chaparro, 1997; Sequeira, 2005; Medina, 2016). O modo de operação dos atuais meios de comunicação acentua a falta de informação devido o modo de atuação de toda estrutura jornalística existente. Medina define tal situação como "aumento da incomunicação", proporcionada por batalhão de propagandistas que atua na formação e controle da opinião pública (Lima, 1993, p. 75).

O jornalismo diário, de gabinete, exercido dentro das redações pode transformar-se em jornalismo investigativo quando há ação diferenciada, postura proativa do repórter. O renascimento do JI pode ocorrer também fora das redações, através do jornalismo independente, desatrelado de chefias, mas com projeto estruturado e objetivo a ser alcançado. É quando o profissional utiliza técnicas e estratégias peculiares que não fazem parte da rotina das hard news. E também quando torna público acontecimentos que grupos de poder querem esconder da sociedade (Sequeira, 2005, p. 62). Exemplo desse novo modo de se fazer jornalismo investigativo é desenvolvido por agências de reportagens independentes dos meios tradicionais de financiamento para meios de comunicação. Elas recebem aportes através de doações de fundações privadas brasileiras e internacionais, patrocínios a projetos especiais através de editais, crowndfunding e financiamento dos leitores. Como a Agência Pública de Jornalismo Investigativo, o The Intercept Brasil, Ponte Jornalismo, Amazônia Real, entre outros. 


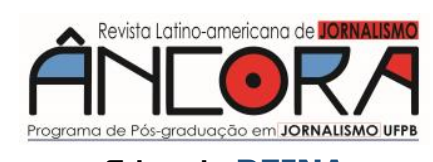

Eduardo REINA

Na mídia convencional, a cobertura investigativa depende de materiais reunidos ou gerados a partir da própria iniciativa do repórter (Hunter et al, 2013, p. 10). É função do JI seguir o rastro de histórias ou acontecimento que, em determinado momento, foram notícia, mas acabaram saindo das páginas dos jornais - com o objetivo de checar se esses fatos, da forma como foram divulgados, não trouxeram prejuízo à sociedade (Sequeira, 2005, p. 113). No JI, o melhor da história (ou a melhor história) quase sempre está encoberto. Mas pode acontecer o contrário, o material está ali, à mostra, esperando que o repórter o veja e perceba que existe novo ponto de partida para uma boa investigação.

O Jornalismo Investigativo implica em trazer à luz questões que permaneciam ocultas, seja deliberadamente por uma pessoa em uma posição de poder, ou acidentalmente, por trás de uma massa desconexa de fatos e circunstâncias - e a análise e apresentação de todos os seus fatos relevantes ao público. Dessa forma, o jornalismo investigativo contribui crucialmente para a liberdade de expressão e a liberdade de informação (Hunter et al, 2013, p. 88).

Sem credibilidade não há comunicação (Dines, 1986). Credibilidade essa que vem mudando de sentido ao longo dos tempos, segundo Abramo (1988), ao apontar que com a crise política e o golpe de 1964, os jornais passaram a cuidar muito da forma, o que vem substituindo a qualidade. Deve estar pautada e atrelada ao tripé jornalismo-proatividade-ética, sempre desenvolvido por metodologia particular em cada repórter, calcada em lista de técnicas e critérios que devem levar em conta a prática do bom jornalismo. Estes critérios e condições de ação específicas do campo jornalístico atual são apresentadas como condição indispensável do fazer jornalismo investigativo hoje.

\section{Considerações finais}

A partir dos resultados encontrados durante esta pesquisa considera-se comprovada a hipótese de que o JI pode revelar o crime de sequestro de bebês e crianças, filhos de militantes de esquerda, que esteve oculto na historiografia, 
na grande imprensa e estudos acadêmicos porque houve construção de narrativa direcionada pelos militares para formatar a história conforme seus interesses. E foi fator contribuinte para que tal crime permanecesse esquecido dentro da História do Brasil e opinião nacional.

A manutenção do assunto fora da pauta da grande mídia reflete a força e a estrutura de Poder existente na sociedade brasileira, onde os fatos são veiculados sob a ótica de interesses da classe que mantém o comando e traz como consequência natural a imposição de seus valores e dominação/controle.

A comprovação da linha de raciocínio que delineou as hipóteses deste trabalho demonstra que ainda estão em vigência resquícios do regime totalitário que têm como objetivo invisibilizar a história de seus oponentes, apagar da história geral a vida dessas pessoas. Esta pesquisa identificou a maneira como o assunto foi tratado ao longo da história e a forma de construção de narrativas com base em versões militares.

Na revisão quantitativa de matérias jornalísticas identificadas em 12 anos de publicações dos jornais Folha de S.Paulo, O Estado de São Paulo, O Globo e Estado de Minas - de 25/4/2003 a 18/3/2014 - foi possível observar que os repórteres foram pautados por ações de fontes em efemérides da ditadura brasileira ou então focaram o assunto de interesse dessas próprias fontes em momentos específicos, o que comprova a hipótese básica deste estudo. A revisão bibliográfica de centena e meia de livros mostra a homogeinidade de fontes militares como base dos textos e a reprodução de informações e narrativas em várias obras, que tiveram como gênese os discursos/documentos/personagens ligados às forças militares. Mostra ainda que a mensagem assim disseminada influi diretamente na percepção dos fatos históricos sob o viés de um dos lados nessa disputa.

A arquitetura utilizada na construção da narrativa dessa fase da história, ainda segundo as premissas estudadas, consegue manter as forças militares limpas de qualquer mácula e mantém a morte social das vítimas desse crime de Estado. Foi possível verificar que o plano de comunicação posto em prática, 


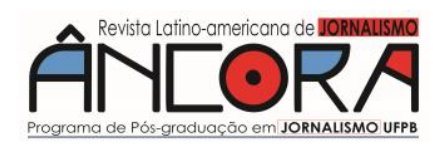

Eduardo REINA

o controle da narratividade, conceitua-se como uma ferramenta ideológica, capaz de impactar e descredibilizar e/ou falsear ideias que estão postas e aceitas tanto pela população como pelo meio acadêmico e imprensa. Análise decorrente do estudo aponta que a esquerda tinha conhecimento da importância do uso eficiente dos meios de comunicação para propagandear suas ações e ganhar adesão popular. Mas a hostilizava e negava.

Contudo, pode-se apontar que o JI tem capacidade de, dentro de ação ética, proativa e planejada descobrir ações, fatos e personagens que permaneceram ocultos no último meio século e que, de certo modo, forjaram um inconsciente coletivo nacional de que a ditadura brasileira foi branda e necessária. Foram descobertos 19 casos desse crime no Brasil (Reina, 2019). Tudo o que está exposto neste estudo demonstra que o jornalismo, queiram ou não, foi, é e será o espaço crítico e de registro do presente e do passado (Dines, 1986). É o jornalismo que continua a indagar de que maneira a história tem sido contada aos brasileiros. O repórter, como um trabalhador comum num sistema de mídia atrelado ao capital, está sujeito a toda sorte de contradições e relações de poder do processo produtivo nas redações. O que demonstra a necessidade de uma proatividade diferenciada, que deve ser desempenhada num ambiente de liberdade total, de imprensa e social, para que cumpra sua função social (Medina, 2016, 2003) (Dines, 1986).

\section{Referências}

ABRAMO, Cláudio. A regra do jogo. São Paulo: Companhia das Letras, 1988.

ALTHUSSER, Louis. Ideologia e aparelhos ideológicos de Estado notas para uma investigação. Lisboa: Editorial Presença, 1970.

BARRETO, Anna Flávia Arruda Lanna. Memória de histórias de violação dos direitos humanos durante as ditaduras militares no Brasil e no Cone Sul. Artigo apresentado Seminário 1964-2014: um olhar crítico para não esquecer. Universidade Federal de Minas Gerais, Belo Horizonte, 2014. BAUMAN, Zygmunt. Modernidade Líquida. Rio de Janeiro: Zahar, 2014a. BOURDIEU, Pierre. O poder simbólico. Lisboa: Difusão Editorial, 1989. 
BURGH, Hugo de. Jornalismo investigativo - contexto e prática. São Paulo: Editora Roca, 2008.

CAMPOS FILHO, Romualdo Pessoa. Guerrilha do Araguaia - a esquerda em armas. São Paulo: Anita Garibaldi, 2012.

CARDOSO, Irene de Arruda Ribeiro. Para uma crítica do presente. São Paulo: Editora 34, 2001.

CHAPARRO, Manuel Carlos. Jornalismo: discurso em dois gêneros. Tese de livre-docência apresentada na ECA-USP, São Paulo, 1997.

COMISSÃO DA VERDADE DO ESTADO DE SÃO PAULO. Infância roubada Crianças atingidas pela Ditadura Militar no Brasil. São Paulo: Edição da Assembleia Legislativa do Estado de São Paulo, 2014.

DINES, Alberto. 0 papel do jornal - uma releitura. São Paulo: Summus Editorial, 1986.

DUHALDE, Eduardo Luis. El Estado Terrorista Argentino. Bueno Aires: Colihue, 2013.

ENZENSBERGER, Hans Magnus. Elementos para uma teoria dos meios de comunicação. Rio de Janeiro: Tempo Brasileiro, 1978. FICO, Carlos. Reinventando o otimismo - ditadura, propaganda e imaginário social no Brasil. Rio de Janeiro: Editora FGV, 1997.

FIGUEIRA, Ricardo Rezende. A justiça do lobo - posseiros e padres do Araguaia. Petrópolis: Vozes, 1986.

FORTES, Leandro. Jornalismo investigativo. São Paulo: Contexto, 2005. FUNDAÇÃO MAURÍCIO GRABOIS; ARROYO, Angelo. Relatório sobre a luta no Araguaia. São Paulo: Anita Garibaldi, 2009.

GASPARI, Elio. A ditadura escancarada. São Paulo: Companhia das Letras, 2002.

HABERMAS, Jurgen. Mudança estrutural da esfera pública. Rio de Janeiro: Tempo Brasileiro, 1984.

HUNTER, Mark Lee, e HANSON, Nils. A investigação a partir de histórias. Um manual para jornalistas investigativos. Paris: Unesco Publishing, 2013.

JABINE, Thomas B.; CLAUDE, Richard Pierre; SOUZA, Gilson César Cardoso de. Direitos humanos e estatísticas: o arquivo posto a nu. São Paulo: Edusp, 2007.

JIMENEZ, José Vargas. Bacaba - memórias de um guerreiro de selva da guerrilha do Araguaia. Campo Grande: Edição do Autor, 2007. KOVACH, Bill; ROSENSTIEL, Tom. Os elementos do jornalismo - o que os jornalistas devem saber e o público exigir. São Paulo: Geração Editorial, 2003.

LIMA, Edvaldo Pereira. Páginas ampliadas - o livro reportagem como extensão do jornalismo e da literatura. São Paulo: Editora Unicamp, 1993.

LOPES, Dirceu Fernandes; PROENÇA, José Luiz (orgs). Jornalismo investigativo. São Paulo: Publisher Brasil, 2003. 


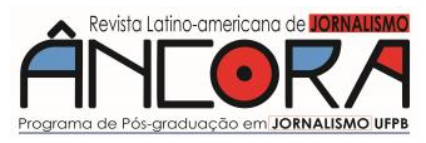

Eduardo REINA

MADRES Y FAMILIARES DE URUGUAYOS DETENIDOS DESAPARECIDOS. A Todos Ellos. Informe de Madres y Familiares de Uruguayos

Detenidos Desaparecidos. Montevideo, 2004.

MEDINA, Cremilda. Jornalismo na Sociedade Urbana e Industrial. São

Paulo: Summus Editorial, 1978.

MEDINA, Cremilda. A arte de tecer o presente - narrativa e cotidiano.

São Paulo: Summus Editorial, 2003.

MEDINA, Cremilda. Ato presencial - mistério e transformação. São

Paulo: Casa da Serra, 2016.

MIRANDA, Nilmário; TIBÚRCIO, Carlos. Dos fillhos deste solo - mortos e desaparecidos durante a ditadura militar: a responsabilidade do Estado. São Paulo: Boitempo, 2008 (2a edição).

MORAIS, Taís; SILVA, Eumano. Operação Araguaia - os arquivos

secretos da guerrilha. São Paulo: Geração Editorial, 2005.

NOSSA, Leonêncio. Mata! $\mathbf{O}$ major Curió e as guerrilhas do Araguaia.

São Paulo: Companhia das Letras, 2012.

OLIVEIRA, Hermes de Araújo. Guerra Revolucionária. Rio de Janeiro:

Biblioteca do Exército Editora, 1965.

PADRÓS, Enrique Serra. Como el Uruguay no hay-: terror de Estado e segurança nacional Uruguai (1968-1985): do pachecato à ditadura civil-militar. Tese (Doutorado em História) - Universidade Federal do Rio Grande do Sul, Instituto de Filosofia e Ciência Humanas, Porto Alegre: 2005. PADRÓS, Enrique Serra (organizador). A ditadura de segurança nacional no Rio Grande do Sul (1964-1985): História e memória. Repressão e resistência nos "anos de chumbo", Volume 2. Porto Alegre: Corag, 2009.

PADRÓS, Enrique Serra (org.); NUNES, Carmen Lúcia da Silveira; LOPEZ, Vanessa Albertinence; FERNANDES, Ananda Simões (Orgs.). Memória, verdade e justiça [recurso eletrônico]: as marcas das ditaduras do Cone Sul. Porto Alegre: Assembleia Legislativa do Rio Grande do Sul, 2011. PADRÓS, Enrique Serra. Guerra contra as crianças: práticas de sequestro, desaparecimento e apropriação de identidade no século XX - "Butim de Guerra" no Cone Sul da Segurança Nacional.

Apresentado no XI Encontro Estadual de História, Universidade Federal do Rio Grande do Sul - Associação Nacional de História - Seção Rio Grande do Sul, Porto Alegre, 2012.

PCdoB, e vários autores. Guerrilha do Araguaia - uma epopeia pela liberdade. São Paulo: Anita Garibaldi, 2005.

PIGLIA, Ricardo. La forma inicial - conversaciones em Princeton.

Buenos Aires: Eterna Cadencia, 2015.

POMAR, Wladimir. Araguaia - 0 partido e a Guerrilha - Documentos inéditos. São Paulo: Brasil Debates, 1980. 
QUESADA, Montserrat. La investigacion periodística - el caso español. Espanha: Editorial Ariel, 1987.

REINA, Eduardo. Depois da rua Tutoia. São Paulo: 11 Editora, 2016. REINA, Eduardo. Cativeiro sem fim. São Paulo: Alameda Editorial, 2019. SÁ, Glênio. Araguaia - relato de um guerrilheiro. São Paulo: Anita Garibaldi, 2004.

SÁBATO, Ernesto (org.). Informe da Comissão Nacional sobre o Desaparecimento de Pessoas na Argentina - $\mathbf{3 0}$ mil mortos, 340 campos de concentração: o saldo da repressão militar na Argentina. Porto Alegre: LP\&M, 1984.

SANJURJO, Liliana. Sangue, identidade e verdade - memórias sobre o passado ditatorial na Argentina. São Paulo: EdUFSCar, 2018.

SANTORO, Daniel. Técnicas de investigación. México: Editora Fondo de Cultura Económica, 2004.

SECRETARIA ESPECIAL DE DIREITOS HUMANOS DA PRESIDÊNCIA DA REPÚBLICA. Direito à Memória e à Verdade - histórias de meninas e meninos marcados pela ditadura. Secretaria Especial de Direitos Humanos. Brasília: Presidência da República, 2009.

SEQUEIRA, Cleofe Monteiro. Jornalismo investigativo - o fato por trás da notícia. São Paulo: Summus Editorial, 2005.

SOUZA, Percival. Narcoditadura - o caso Tim Lopes, crime organizado e Jornalismo Investigativo no Brasil. São Paulo: Labortexto Editorial, 2002.

STUDART, Hugo. A lei da selva. São Paulo: Geração Editorial, 2006. STUDART, Hugo. Em algum lugar das selvas amazônicas: as memórias dos guerrilheiros do Araguaia (1966-1974). Brasília, 2013. VALENTE, Rubens. Os fuzis e as flechas - história de sangue e resistência indígena na ditadura. São Paulo: Companhia das Letras, 2017.

VISACRO, Alessandro. Guerra irregular - terrorismo, guerrilha e movimentos de resistência ao longo da história. São Paulo: Contexto, 2009.

VISACRO, Alessandro. A guerra na era da informação. São Paulo: Contexto, 2018. 